The Israeli Journal of Aquaculture - Bamidgeh, IJA_72.2020.1134658, 12 pages

CCBY-NC-ND-4.0 • https://doi.org/10.46989/001c.21508

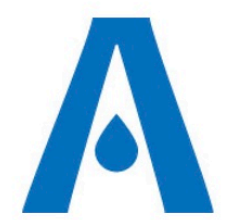

The IJA is a peer-reviewed open-access, electronic journal, freely available without charge to users

Produced by the AquacultureHub non-profit Foundation Sale of $I J A$ papers is strictly forbidden

\title{
The use of otolith shape to identify stocks of Konosirus punctatus
}

\section{Songzhang Li ${ }^{1,2}$, Xianwen Wang ${ }^{4}$, Haixia Wang ${ }^{4}$, Chunzhi $\mathrm{Wu}^{5}$, Huixiang Zhan ${ }^{6}$, Shengqi Su, ${ }^{1 *}$, Tianxiang $\mathrm{GaO}^{3 *}$, Tao $\mathrm{He}^{1,2 *}$}

${ }^{1}$ College of Fisheries, Southwest University, Chongqing 400715, P. R. China

${ }^{2}$ Key Laboratory of Freshwater Fish Reproduction and Development (Ministry of Education)

${ }^{3}$ Fishery College, Zhejiang Ocean University, Zhoushan 316022, P.R. China

${ }^{4}$ Hezhang Fisheries Technology Extension Station, Bijie 553200, P.R China

${ }^{5}$ Hezhang Center for Animal Disease Control and Prevention, Bijie 553200, P.R China

${ }^{6}$ Bijie Fisheries Technology Extension Station, Bijie 551700, P.R China

Key words: Otolith morphology; Shape indices; Fourier analysis; Stocks identification; Discrimination function

\begin{abstract}
Konosirus punctatus is an important economic fish in the Northwest Pacific Ocean, especially along the coast of China, and an important substitute in the marine ecosystem. The aim of this study is to quantify the variation of sagittal shapes to discriminate the $K$. punctatus stocks between China coasts (Wei Hai, Yan Tai, Zhou Shan, Wen Zhou, Dong Ying, Hai Kou and Qing Dao) and Aomori $(\mathrm{Am})$ in Japan by comparing the sagittal morphometric features. The sagitta variation of eight $K$. punctatus stocks was examined using nine shape indices (Roundness, Circularity, Form-factor, Rectangularity, Ellipticity, Radius ratio, Feret ratio, Aspect ratio and Surface density). Multiple comparisons on shape indices showed that three shape indices (Roundness, Feret ratio and Surface density) have significant differences between nine stocks. The comprehensive judgment accuracy rate is $54.5 \%$. Based on the Fourier coefficient eight Fourier parameters can fit the shape of sagittal. The comprehensive judgment accuracy rate is $56.1 \%$. The results showed that the otolith morphology was not significantly different between seven China stocks, while the China stocks showed a large sagittal morphological difference from the Japanese stock. It could be related to environmental factors and geographical conditions in various sea areas.
\end{abstract}

* Corresponding author. Tel.: +86 2368251196, e-mail: hh1985@swu.edu.cn;

gaotianxiang0611@163.com; sushengqi@swu.edu.cn 


\section{Introduction}

Otoliths are important in the life history and population dynamics of fish because they can provide information on microstructure, microchemistry and morphology (Popper et al., 2005). Three pairs of otolith (sagittae, lapilli, and asterisci) are species specific on shapes and morphologies. Among them, sagittae has the most unique characteristics because it exhibits a species-specific morphology, but less variation within a species (Campana, 2004). Some factors can affect morphological variation of sagittae, such as age, genetic factors, environmental conditions (Vignon et al., 2010), growth rate, feeding history and habitat (Lombarte et al., 1993). Therefore, the analysis of sagittal size and shape has become a useful tool for stock discrimination and species identification (He et al., 2017). Consequently, morphology can differ between populations of the same species at different locations. Individuals and phylogenetic patterns of the same species or even the same gender can be reflected in their morphology (Lombarte et al., 2007).

Konosirus punctatus belongs to the other Clupeiformes, the family Clupeidae, the subfamily Dorosomatinae. It is a coastal warm-water fish widely distributed along the southeast coast of China, the coast of North Korea, and the south coast of Japan. $K$. punctatus is a secondary economic fish, and has a relatively fixed migration pattern. It migrates back and forth between spawning grounds in shallower coastal waters and overwintering grounds in deeper seas every year. The stocks of Bohai Sea and Yellow Sea have a common spawning ground in the southeast area of the Yellow Sea.

The dramatic climate changes during the Pleistocene Ice Age had a huge impact on the distribution and number of organisms (Dynesius et al., 2000). The Pacific Northwest is the main habitat of $K$. punctatus. During the late Quaternary glacial period, the area and structure of the marginal sea had undergone tremendous changes in the Northwest Pacific due to large changes in sea level (Wang, 1999). The Northwest Pacific has a complex ocean current pattern, which may promote the proliferation of marine fish after the end of the ice age, resulting in the mixing of local groups.

Studies have shown that many marine fishes have a significant population spatial structure. Due to a certain level of communication with each other, they can be divided into several related and relatively independent subpopulations. The complex geographical environment and climate change combined with the life history characteristics of fishes have caused many different population structure patterns in the Northwest Pacific, especially between local stocks along the coast of China and Japan (Nurul Ridani et al., 2015). The fish population structure is critical to the management of fishery resources. Ignoring the fish population structure may bring unpredicTable overfishing risks (Hutchings, 2000). Many fish have been detected with significant population structure differentiation in the Northwest Pacific, such as Chelon haematocheilus (Liu et al., 2007), Pennahia argentata (Song et al., 2020) and Perccottus glenii (Pavlov et al., 2020).

In this study, we distinguished $K$. punctatus stocks picked from the coast of China and Japan randomly by otolith morphology which had advantages over traditional morphological identification. This was the first time to identify the $K$. punctatus stocks in the Western Pacific through otolith shape analysis and Fourier analysis.

\section{Sample collection}

\section{Materials and Methods}

Fish were collected from China's four major sea areas and Japan. Samples were collected at Dong Ying (DY) belongs to the Bohai Sea, Yan Tai (YT), Wei Hai (WH), Qing Dao (QD) belongs to the Yellow Sea, Zhou Shan (ZS), Wen Zhou (WZ) belongs to the Donghai Sea, Hai Kou (HK) belongs to the South China Sea and Aomori (Ao) belongs to Japan, from April 2006 to May 2011 (Figure 1; Table 1). Fish with a similar size were compared to avoid confounding effects in the otolith shape due to ontogeny. 


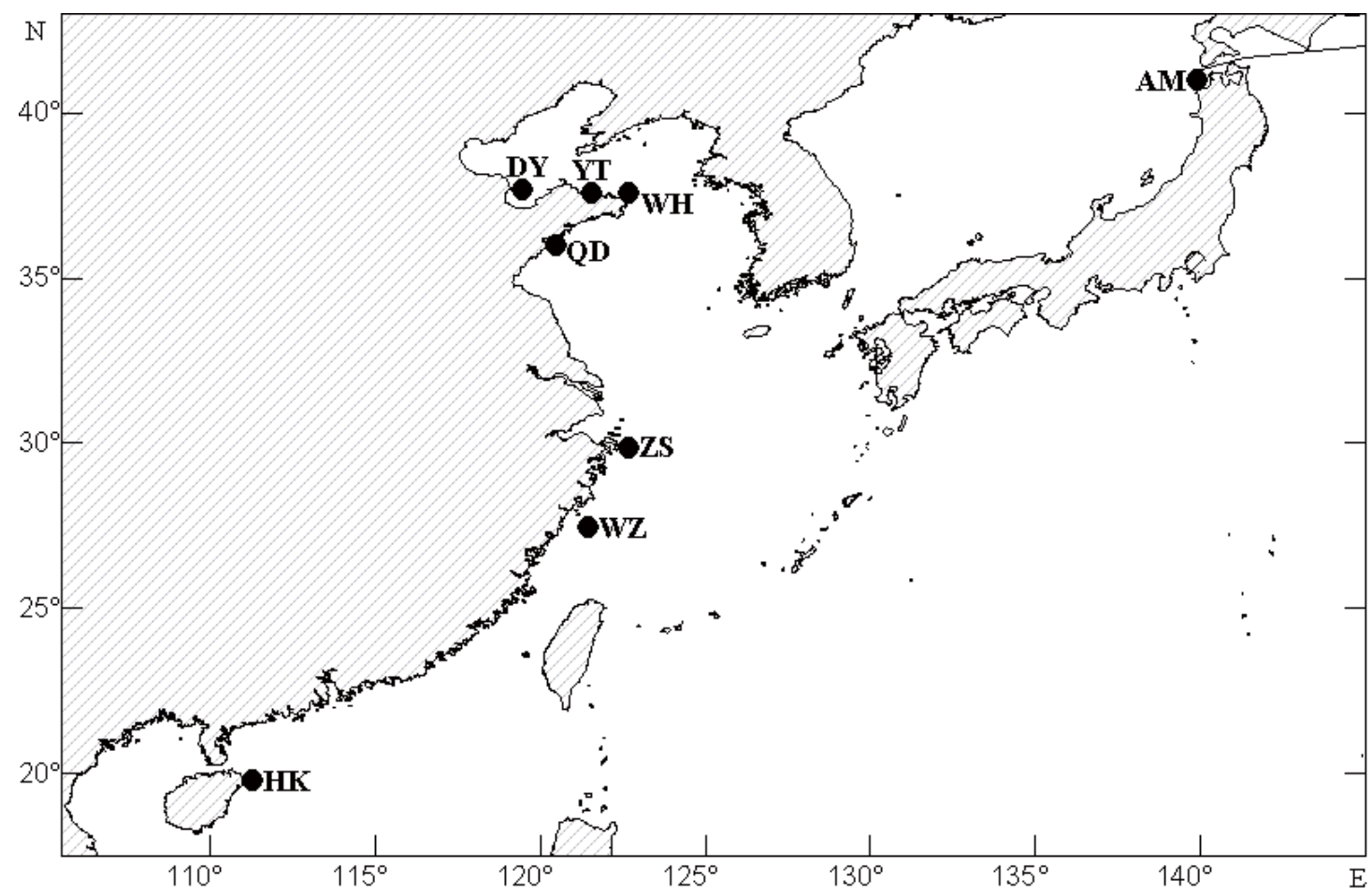

Figure 1 Sampling locations of $K$. punctatus: Wei Hai (WH), Yan Tai (YT), Zhou Shan (ZS), Wen Zhou (WZ), Dong Ying (DY), Hai Kou (HK), Qing Dao (QD), and Aomori (AM).

Table 1 Sample information of $K$. punctatus

\begin{tabular}{ccccccc}
\hline Site & Abbre & Position & Time & Size & Total length $(\mathrm{mm})$ & Body weight $(\mathrm{g})$ \\
\hline Weihai & WH & $37.37 \mathrm{~N} \mathrm{121.77 \textrm {E }}$ & $2007-5$ & 19 & $155.7 \pm 4.3$ & $59.19 \pm 4.89$ \\
Zhoushan & ZS & $30.88 \mathrm{~N} 122.90 \mathrm{E}$ & $2006-5$ & 17 & $150.4 \pm 3.8$ & $53.13 \pm 4.15$ \\
Dongying & DY & $37.81 \mathrm{~N} 119.23 \mathrm{E}$ & $2007-4$ & 27 & $153.0 \pm 3.3$ & $55.91 \pm 3.69$ \\
Yantai & YT & $37.59 \mathrm{~N} 120.50 \mathrm{E}$ & $2007-5$ & 20 & $151.5 \pm 4.1$ & $54.34 \pm 4.44$ \\
Haikou & HK & $22.58 \mathrm{~N} 114.58 \mathrm{E}$ & $2006-4$ & 28 & $154.8 \pm 5.7$ & $58.17 \pm 6.55$ \\
Qingdao & QD & $36.01 \mathrm{~N} 120.34 \mathrm{E}$ & $2006-4$ & 24 & $157.9 \pm 4.1$ & $61.72 \pm 4.19$ \\
Wenzhou & WZ & $27.81 \mathrm{~N} 120.85 \mathrm{E}$ & $2009-4$ & 42 & $155.2 \pm 4.2$ & $58.59 \pm 4.91$ \\
Aomori & Ao & $40.58 \mathrm{~N} 139.48 \mathrm{E}$ & $2006-5$ & 21 & $150.3 \pm 7.3$ & $53.36 \pm 8.13$ \\
\hline
\end{tabular}

Otoliths preparation

Both left and right sagittae were removed from each fish, and then cleaned with ultrasound (KQ3200) for 30 min after soaking in Milli-Q water for an hour to further remove tissue residuals and organics. Samples were then rinsed with Milli-Q water and dry to constant weight in a drying oven.

The left sagitta was examined and photographed using a Nikon SMZ800 microscope equipped with a digital camera (Nikon DN100) (Figure 2). However, when the left sagitta was damaged, the right sagitta was used. If both otoliths were lost, the fish was discarded from the otolith shape analysis. Sagittae were positioned on a concave side before the image was taken. When the right otolith was used, the image was horizontally flipped using a standard image analysis technique to ensure that the rostrum was orientated to the right on the screen for each specimen.

Otolith shape analysis

The comparison of otolith shape was based on both the shape index analysis and Fourier analysis.

Shape index analysis: Using the image from each otolith, nine size parameters were calculated: Otolith weight (OW), Feret length (FL), Feret width (FW), Otolith perimeter (P), 
Otolith area (A), maximum radius (Rmax), minimum radius (Rmin), maximum Feret length (Fmax) and minimum Feret length (Fmin). Feret length and Feret width are the length and width of a box, which encloses the trace of the otolith (Tuset et al., 2003). All measurements were taken using the Image-Pro Plus6.0 program.

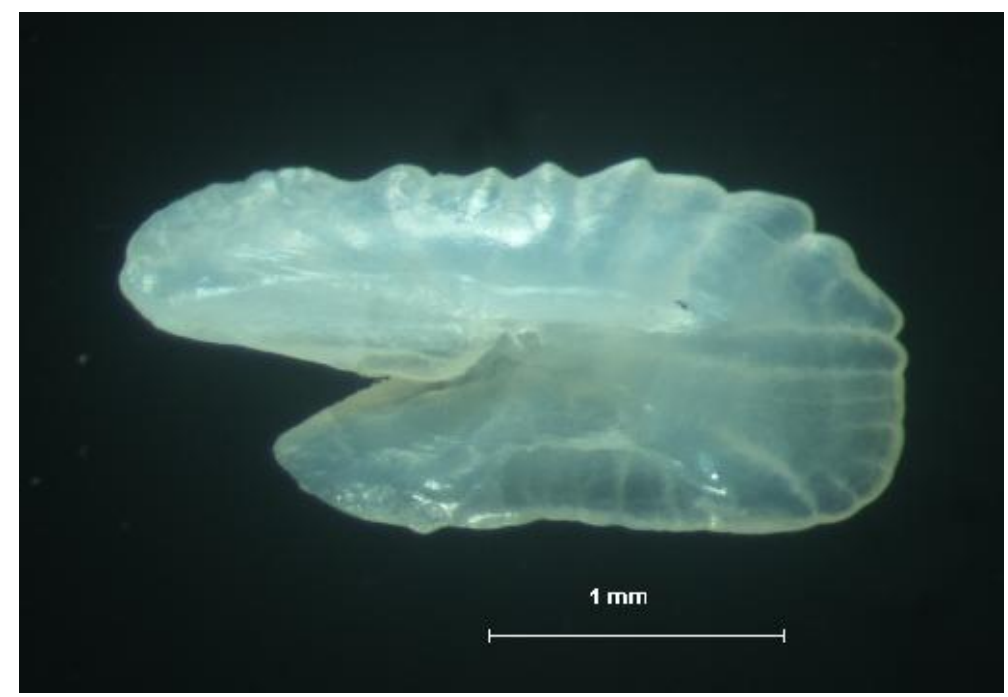

Figure 2 Otolith illustration of $K$. punctatus

Nine shape indices were obtained by calculating the above nine parameters in various ways and the equations are presented in Table 2 . Roundness and circularity provide information on the similarity of various features to a perfect circle, taking a minimum value of 1 and 12.57, respectively. The form-factor is the mean value to estimate the irregularity of surface area, taking the value of 1.0 when it is a perfect circle and $<1.0$ when it is an irregular shape. Rectangularity describes the variations of length and width with respect to the area with the value of 1.0 being a perfect square. Ellipticity indicates if the changes in the axes are proportional. The radius ratio, Feret ratio and aspect ratio are the results of the division of the length by the width, and a larger value shows a more elongated shape (Ponton, 2006). Surface density indicates the thickness of otolith, and a higher value shows a thicker otolith.

Table 2 Size dimension parameters and shape indices of $K$. punctatus otolith

\begin{tabular}{ll}
\hline Size parameter & Shape index \\
\hline Area $(A)$ & Roundness $\left(X_{1}\right)=4 A / n F L^{2}$ \\
Perimeter $(P)$ & Form-factor $\left(X_{2}\right)=4 \Pi A / P^{2}$ \\
Feret length $(F L)$ & Circularity $\left(X_{3}\right)=P^{2} / A$ \\
Feret width $(F W)$ & Rectangularity $\left(X_{4}\right)=A /(F L \times F W)$ \\
Maximum radius $\left(R_{\max }\right)$ & Ellipticity $\left(X_{5}\right)=(F L-F W) /(F L+F W)$ \\
Minimum radius $\left(R_{\min }\right)$ & Radius ratio $\left(X_{6}\right)=R_{\max } / R_{\min }$ \\
Maximum Feret length $\left(F_{\max }\right)$ & Feret ratio $\left(X_{7}\right)=F_{\max } / F_{\min }$ \\
Minimum Feret length $\left(F_{\min }\right)$ & Aspect ratio $\left(X_{8}\right)=F L / F W$ \\
Otolith weight $(O W)$ & Surface Density $\left(X_{9}\right)=O W / A$ \\
\hline
\end{tabular}

Fourier analysis: The Fourier analysis decomposes the contour of an irregular 2dimension image and forms a set of simpler components (harmonics). Each successive harmonic can add more information on the property of shape morphometrics (Campana et al., 1993). The Shape 1.3 software was used to extract the contours of the sagitta outline in preparation for Fourier analysis. The ChcViewer program generated several coordinates 
$(x, y)$ best describing the outline shape of the sagittae. For each sagitta, 20 harmonics were generated using the CHC2NEF program. Each harmonic consisted of four coefficients resulting in 80 coefficients per otolith. The program standardizes the size and orientation, giving the first three coefficients with fixed values of $A=1, B=C=0$. Everyone was therefore represented by 77 unique coefficients (Longmore et al., 2010).

Principal component analysis: To reduce the dimensionality of the data, the principal component analysis was performed on both shape indices and Fourier coefficients by SPSS18.0. The significant principal components (PCs) were established according to the published methods (Duarte-Neto et al., 2008; Humphreys et al., 2006; Kelly, 2007). The PC scores were used in the multivariate analysis between regions where fish were collected. Data were then tested for normality and homogeneity of variance using SPSS18.0. Any variables (shape indices/coefficients) that displayed a normal distribution and homogeneity of variance were tested for differences between sampling sites using univariate ANOVA (SPSS18.0).

Discriminant function analysis: Fisher's discriminant function was used because it combines two or more measurements to improve the power to discriminate species (Goldstein et al., 1978). Discriminant function analysis was carried out to determine the proportion of individuals that could be correctly assigned to their capture site based on sagittal shape variables (shape indices/coefficients). These variables were then tested for univariate correlation with otolith length and correlation between variables to prevent any multicollinearity between variables as correlated variables can result in the use of redundant variables and a false outcome. Analysis of covariance was used to examine the influence of otolith length on each shape variable using SPSS 18.0(He Tao et al., 2018).

Shape index analysis

\section{Results}

No significant differences were found (MANOVA, $p=0.05$ ) between the shape indices of right and left otoliths (Table S1).

Table S1 Analysis of variance and t-test for the left and right sagittae $(P=0.05, n=42)$.

\begin{tabular}{ccccccc}
\hline \multirow{2}{*}{ Parameter } & \multicolumn{2}{c}{ means \pm S.D. } & & \multicolumn{2}{c}{ ANOVA } & t-test \\
\cline { 2 - 3 } \cline { 6 - 7 }$X_{1}$ & Left sagittae & Right sagittae & & $F$ & & $P$ \\
$X_{2}$ & $0.455 \pm 0.025$ & $0.458 \pm 0.027$ & & 0.220 & 0.640 & 0.147 \\
$X_{3}$ & $23.000 \pm 1.440$ & $22.967 \pm 1.412$ & & 0.015 & 0.903 & 0.804 \\
$X_{4}$ & $0.707 \pm 0.019$ & $0.708 \pm 0.020$ & & 0.164 & 0.687 & 0.367 \\
$X_{5}$ & $0.328 \pm 0.022$ & $0.327 \pm 0.022$ & & 0.091 & 0.763 & 0.347 \\
$X_{6}$ & $2.636 \pm 0.215$ & $2.675 \pm 0.329$ & & 0.429 & 0.514 & 0.239 \\
$X_{7}$ & $2.091 \pm 0.101$ & $2.084 \pm 0.104$ & & 0.118 & 0.732 & 0.238 \\
$X_{8}$ & $1.980 \pm 0.099$ & $1.974 \pm 0.097$ & & 0.093 & 0.761 & 0.328 \\
$X_{9}$ & $0.715 \pm 0.040$ & $0.711 \pm 0.032$ & & 0.285 & 0.595 & 0.170 \\
\hline
\end{tabular}

Nine shape indices were tested for significant differences among eight locations using one-way ANOVA $(P=0.05)$. There was no significant difference between $\mathrm{WH}$ and $Z \mathrm{~S}, \mathrm{YT}$ stocks, but the shape indices of the WH stock were significantly different from the DY stock in the $X_{5}, X_{7}$ indices, HK stock in the $X_{1}, X_{7}, X_{9}$ indices, QD stock in the $X_{1}, X_{5}, X_{7}, X_{9}$ indices, WZ stock in the $X_{4}, X_{9}$ indices, and $A 0$ stock in the $X_{1}$ and $X_{5}-X_{9}$ indices. The rest of the results were listed in the Table $\mathbf{3}$ (see at the last page of the article).

Principal component analysis showed that the first three PCs were relevant with eigenvalues of 5.237, 1.807 and 1.116 (Table S2), respectively, according to the 'broken stick model' on sagittal contours (Jackson, 1993) and explained $90.673 \%$ of the overall variance. The first PC, accounting for $58.193 \%$ of the total variance, was mainly determined by four shape indices $\left(X_{1}, X_{5}, X_{7}\right.$ and $\left.X_{8}\right)$. 
Table S2 Loadings and eigenvalues of the first three principal components of shape indices of sagittae of $K$. punctatus

\begin{tabular}{|c|c|c|c|}
\hline \multirow{2}{*}{ Otolith shape indices } & \multicolumn{3}{|c|}{ Principal components } \\
\hline & 1 & 2 & 3 \\
\hline $\mathrm{X}_{1}$ & -0.9532 & -0.2189 & 0.0889 \\
\hline$x_{2}$ & -0.7435 & 0.6233 & -0.0387 \\
\hline$X_{3}$ & 0.7431 & -0.6246 & 0.0409 \\
\hline $\mathrm{X}_{4}$ & -0.6600 & 0.3068 & 0.5109 \\
\hline$X_{5}$ & 0.8354 & 0.4937 & 0.2160 \\
\hline$X_{6}$ & 0.7718 & -0.3136 & -0.0642 \\
\hline$X_{7}$ & 0.8903 & 0.3917 & 0.0358 \\
\hline $\mathrm{X}_{8}$ & 0.8373 & 0.4932 & 0.2100 \\
\hline$X_{9}$ & 0.0280 & -0.3838 & 0.8650 \\
\hline Eigenvalue & 5.237 & 1.807 & 1.116 \\
\hline Variance explained & 58.193 & 20.076 & 12.404 \\
\hline Cumulative percentage & 58.193 & 78.269 & 90.673 \\
\hline
\end{tabular}

The second PC, accounting for $20.076 \%$ of the variance, was mostly determined by the $\mathrm{X}_{2}$, and $X_{3}$ indices. In the plot of the first two PCs (Figure 3, see at the last page of the article), the distribution zones of eight stocks are heavily overlapped, especially among Chinese stocks.

Three shape indices $\left(X_{1}, X_{7}\right.$ and $\left.X_{9}\right)$ were screened by Fisher's discriminant analysis to establish the eight discriminant functions for each stock (Table S3).

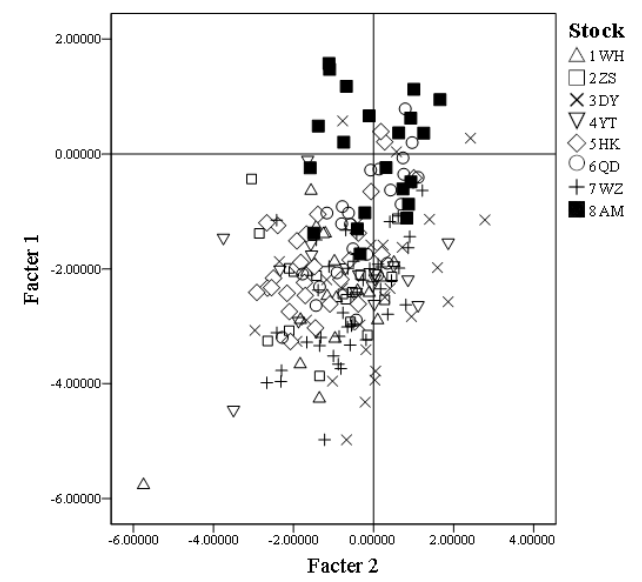

Figure 3 Scatter plot of principal component analysis for otolith shape indices of $K$.

Table S3 Parameters of discriminant functions for eight populations of $K$. punctatus

\begin{tabular}{ccccc}
\hline Stocks & $X_{1}$ & $X_{7}$ & $X_{9}$ & Constant \\
\hline WH & 6298.754 & 1550.213 & 35.957 & -3028.951 \\
ZS & 6275.433 & 1546.309 & 38.550 & -3012.135 \\
DY & 6343.327 & 1567.760 & 66.424 & -3105.393 \\
YT & 6299.670 & 1553.153 & 25.954 & -3029.288 \\
HK & 6240.198 & 1544.079 & 103.043 & -3037.042 \\
QD & 6282.350 & 1560.395 & 68.473 & -3064.539 \\
WZ & 6356.374 & 1567.773 & 70.121 & -3113.487 \\
Ao & 6263.097 & 1570.717 & 181.222 & -3175.984 \\
\hline
\end{tabular}

Where $X_{1}$ is Roundness, $X_{7}$ is Feret ratio, $X_{9}$ is Surface density. 
WH: $Y_{1}=6298.754 X_{1}+1550.213 X_{7}+35.957 X_{9}-3028.951$

$Z S: Y_{2}=6298.754 X_{1}+1546.309 X_{7}+38.55 X_{9}-3012.135$

DY: $Y_{3}=6343.327 X_{1}+1567.76 X_{7}+66.424 X_{9}-3105.393$

YT: $Y_{4}=6299.67 X_{1}+1553.153 X_{7}+25.954 X_{9}-3029.288$

HK: $Y_{5}=6240.198 X_{1}+1544.079 X_{7}+103.043 X_{9}-3037.042$

QD: $Y_{6}=6282.35 X_{1}+1560.395 X_{7}+68.473 X_{9}-3064.539$

$W Z: Y_{7}=6356.374 X_{1}+1567.773 X_{7}+70.121 X_{9}-3113.487$

Ao: $Y_{8}=6263.097 X_{1}+1570.717 X_{7}+181.222 X_{9}-3175.984$

Where $X_{1}$ was Roundness, $X_{7}$ was Feret ratio, $X_{9}$ was Surface density.

When the specimen was assigned, the three shape indices of each sagitta were substituted into the above eight discriminant functions, and the corresponding maximum value $(Y)$ indicated the attribution of each specimen. The results showed that the discriminant function analysis based on sagittal shape indices classified $54.5 \%$ of 198 individuals to the correct location (Table 4). Classification success was highest in the Ao stock with $100 \%$ of 21 individuals classified to their right sampling site. Classification success was $26.3 \%$ of 19 specimens in the WH stock, $23.5 \%$ of 17 individuals in the ZS stock, $3.7 \%$ of 27 individuals in the DY stock, and $55 \%$ of 20 specimens in the GZ stock, respectively.

Table 4 Result of CAD for eight populations of $K$. punctatus

\begin{tabular}{cccccccccc}
\hline Stocks & WH & ZS & DY & YT & HK & QD & WZ & AM & IA (\%) \\
\hline WH & $\mathbf{5}$ & 5 & 0 & 4 & 0 & 1 & 4 & 0 & 26.3 \\
ZS & 4 & $\mathbf{4}$ & 0 & 5 & 0 & 1 & 3 & 0 & 23.5 \\
DY & 2 & 1 & $\mathbf{1}$ & 0 & 3 & 4 & 15 & 1 & 3.7 \\
YT & 3 & 3 & 0 & $\mathbf{1 1}$ & 0 & 1 & 2 & 0 & 55 \\
HK & 0 & 0 & 0 & 0 & $\mathbf{2 2}$ & 2 & 4 & 0 & 78.6 \\
QD & 0 & 2 & 1 & 0 & 4 & $\mathbf{1 1}$ & 6 & 0 & 45.8 \\
WZ & 1 & 0 & 1 & 0 & 1 & 6 & $\mathbf{3 3}$ & 0 & 78.6 \\
AM & 0 & 0 & 0 & 0 & 0 & 0 & 0 & $\mathbf{2 1}$ & 100 \\
TDA (\%) & & & & & & & & & $\mathbf{5 4 . 5}$ \\
\hline IA: identification
\end{tabular}

IA: identification accuracy; TDA: toal discriminant accuracy

\section{Fourier analysis}

The first 20 harmonics explained at least $99.99 \%$ of the otolith variation. PCA was applied to selected Elliptical Fourier Descriptors matrix of otolith contours. Out of 77 Fourier coefficients (FCs) tested, only the first fourteen PCs were significant as determined by their eigenvalues exceeding the threshold eigenvalue $(>1)$ generated by the broken-stick model and their cumulative contribution ratio accounted for $95.06 \%$ of the overall variance. In the plot of the first two PCs, the distribution zones of eight stocks are totally overlapped.

The shape variation (mean $\pm 2 \mathrm{SD}$; i.e. the square root of the eigenvalue of each component) was explained by the first 14 PCs (Table S4). The principal characteristics mainly exhibited by the first four PCs (PC1 and PC2, the dorsal and ventral margins; PC3, the rostrum and posterior margin; PC4, the anterior-ventral margins). Therefore, the rostrum, and dorsal and ventral margins reflected the main variations between the five stocks. 
Table S4 Loadings and eigenvalues of the first 14 principal components of shape indices of sagittae of $K$. punctatus

\begin{tabular}{llllllll}
\hline Principal component & 1 & 2 & 3 & 4 & 5 & 6 & 7 \\
\hline Eigenvalue & 17.38 & 13.88 & 8.26 & 6.41 & 4.74 & 4.52 & 3.26 \\
Variance explained & 22.57 & 18.02 & 10.73 & 8.32 & 6.16 & 5.87 & 4.23 \\
Cumulative percentage & 22.57 & 40.59 & 51.32 & 59.64 & 65.79 & 71.66 & 75.90 \\
\hline Principal component & 8 & 9 & 10 & 11 & 12 & 13 & 14 \\
\hline Eigenvalue & 2.96 & 2.66 & 2.47 & 2.29 & 1.84 & 1.35 & 1.18 \\
Variance explained & 3.85 & 3.45 & 3.21 & 2.98 & 2.39 & 1.75 & 1.53 \\
Cumulative percentage & 79.75 & 83.20 & 86.41 & 89.39 & 91.78 & 93.53 & 95.06 \\
\hline
\end{tabular}

In total, eight Fourier parameters (A02, A08, B02, C08, D01, D05, D06 and D10) were chosen from 77 FCs by Fisher's discriminant analysis, and then were used to establish eight discriminant functions (Table S5).

Table S5 Parameters of discriminant functions for eight populations of $K$. punctatus

\begin{tabular}{cccccccccc}
\hline Stocks & A02 & A08 & B02 & C08 & D01 & D05 & D06 & D10 & Constant \\
\hline WH & -19.11 & 492.62 & 166.51 & 140.37 & 1040.25 & 913.99 & 840.91 & -1541.44 & -311.59 \\
ZS & -62.41 & 696.72 & 168.06 & 54.56 & 1039.98 & 1081.86 & 1164.67 & -1935.16 & -320.70 \\
DY & 31.36 & 534.34 & 188.26 & 336.84 & 1009.20 & 814.12 & 778.59 & -1430.22 & -288.48 \\
YT & -15.84 & 540.38 & 151.44 & 38.30 & 1030.25 & 1021.43 & 825.27 & -1558.11 & -306.21 \\
HK & -57.94 & 454.86 & 83.23 & 83.36 & 1004.89 & 999.06 & 503.13 & -1088.08 & -291.11 \\
QD & -16.60 & 415.05 & 109.30 & 242.72 & 984.19 & 916.80 & 676.67 & -1408.76 & -275.50 \\
WZ & -76.47 & 726.89 & 119.89 & 7.07 & 1008.21 & 1043.13 & 819.12 & -1414.54 & -297.75 \\
Ao & -53.05 & 300.73 & 110.03 & 565.23 & 943.93 & 751.58 & 648.19 & -1009.22 & -256.29 \\
\hline
\end{tabular}

$\mathrm{WH}: \mathrm{Y}_{1}=-19.11 \mathrm{X}_{1}+492.62 \mathrm{X}_{2}+166.51 \mathrm{X}_{3}+140.37 \mathrm{X}_{4}+1040.25 \mathrm{X}_{5}+913.99 \mathrm{X}_{6}+$ $840.91 X_{7}-1541.44 X_{8}-311.59$

ZS: $Y_{2}=-62.41 X_{1}+696.72 X_{2}+168.06 X_{3}+54.56 X_{4}+1039.98 X_{5}+1081.86 X_{6}+$ $1164.67 X_{7}-1935.16 X_{8}-320.7$

DY: $Y_{3}=31.36 X_{1}+534.34 X_{2}+188.26 X_{3}+336.84 X_{4}+1009.2 X_{5}+814.12 X_{6}+$ $778.59 X_{7}-1430.22 X_{8}-288.48$

YT: $Y_{4}=-15.84 X_{1}+540.38 X_{2}+151.44 X_{3}+38.3 X_{4}+1030.25 X_{5}+1021.43 X_{6}+$ $825.27 X_{7}-1558.11 X_{8}-306.21$

$H K: Y_{5}=-57.94 X_{1}+454.86 X_{2}+83.23 X_{3}+83.36 X_{4}+1004.89 X_{5}+999.06 X_{6}+503.13$ $X_{7}-1088.08 X_{8}-291.11$

QD: $Y_{6}=-16.6 X_{1}+415.05 X_{2}+109.3 X_{3}+242.72 X_{4}+984.19 X_{5}+916.8 X_{6}+676.67$ $X_{7}-1408.76 X_{8}-275.5$

$W Z: Y_{7}=-76.47 X_{1}+726.89 X_{2}+119.89 X_{3}+7.07 X_{4}+1008.21 X_{5}+1043.13 X_{6}+$ $819.12 X_{7}-1414.54 X_{8}-297.75$

Ao: $Y_{8}=-53.05 X_{1}+300.73 X_{2}+110.03 X_{3}+565.23 X_{4}+943.93 X_{5}+751.58 X_{6}+$ $648.19 X_{7}-1009.22 X_{8}-256.29$

Where, $X_{1}$ is $A 02, X_{2}$ is $A 08, X_{3}$ is $B 02, X_{4}$ is C08, $X_{5}$ is D01, $X_{6}$ is D05, $X_{7}$ is D06 and $X_{8}$ is D10.

When the sample was assigned, the Fourier coefficients of each sagitta were substituted into the eight discriminant functions, and the corresponding maximum value $(Y)$ indicated the attribution of the samples. The discriminant function analysis classified $56.1 \%$ of overall 198 individuals to the initial locations based on the sagitta FCs. Classification success was highest in Ao location with $81 \%$ of 21 individuals classified to their sampling site. Other results showed in Table 5. 
Table 5 Discriminant results of the otolith in eight. $K$. punctatus pulations

\begin{tabular}{cccccccccc}
\hline Stocks & WH & ZS & DY & YT & HK & QD & WZ & AM & IA (\%) \\
\hline WH & $\mathbf{4}$ & 3 & 3 & 3 & 1 & 1 & 3 & 1 & 21.1 \\
ZS & 2 & $\mathbf{1 0}$ & 0 & 1 & 0 & 0 & 4 & 0 & 58.8 \\
DY & 2 & 0 & $\mathbf{1 7}$ & 0 & 2 & 3 & 0 & 3 & 63.0 \\
YT & 3 & 1 & 2 & $\mathbf{5}$ & 1 & 4 & 4 & 0 & 25.0 \\
HK & 1 & 0 & 0 & 1 & $\mathbf{1 6}$ & 1 & 6 & 3 & 57.1 \\
QD & 0 & 1 & 3 & 1 & 3 & $\mathbf{1 1}$ & 3 & 2 & 45.8 \\
WZ & 0 & 0 & 4 & 1 & 3 & 3 & $\mathbf{3 1}$ & 0 & 73.8 \\
AM & 1 & 0 & 1 & 0 & 0 & 1 & 1 & $\mathbf{1 7}$ & 81.0 \\
TDA (\%) & & & & & & & & & $\mathbf{5 6 . 1}$ \\
\hline
\end{tabular}

IA: identification accuracy; TDA: toal discriminant accuracy

\section{Discussion}

The analysis of shape indices is complicated, it confirms that species identification can be made by the meristic characteristic of an otolith(Tuset et al., 2003). In addition, the statistical analysis of otolith shapes is a more cost-effective and efficient method to differentiate fish stocks or populations than other methods such as the genetic marker discrimination technique, as recent divergence or secondary reproductive contact may result in no apparent difference in gene frequency between stocks (Begg et al., 1999). Compared with the traditional body morphology method, the otolith morphology method has obvious advantages. For example, the otolith sample is easy to store, the operation is highly repeatable, and it is less affected by environmental machinery. In this study, the sagitta variation of eight $K$. punctatus stocks was examined by using nine shape indices. Multiple comparisons of shape indices showed that there was no significant difference among the WH, ZS and YT locations. The same result came to the locations of DY and WZ. The possible explanation is that the $\mathrm{WH}$ and $\mathrm{YT}$ locations are distributed in a similar habitat in the Yellow Sea, resulting in the similar shape morphology of the otolith in these two stocks. Interestingly, although the ZS location was distributed in the West Sea, which was far from the WH and YT locations, the shape indices of ZS location did not show significantly different from the WH and YT locations. Many authors have suggested that Pleistocene climatic oscillations had profound effects in shaping the present phylogeographical patterns and genetic structure of marine species(Larmuseau et al., 2009; Maggs et al., 2008). Therefore, it may lead to the formation of the reproductive isolation of the $K$. punctatus stocks along the Chinese coast. More importantly, the Ao stock which located in Japan had significant differences in morphological variables from each Chinese stock on $X_{1}$ Roundness, $X_{5}$ Ellipticity, $X_{7}$ Feret ratio, $X_{8}$ Aspect ratio, and $X_{9}$ Surface Density. This indicated that the $K$. punctatus of Chinese and Japanese stocks have large differences in otolith morphology. Gwak tested the mtDNA genetic structure of $K$. punctatus in Japan and Korea, and the result showed that there were two distinct $K$. punctatus mtDNA lineages inhabiting the waters of Japan and Korea(Gwak et al., 2015).

The principal component analysis showed as the distribution zones of the eight stocks were overlapped on the plot, it was inferred that eight stocks of $K$. punctatus were difficult to be discriminated by principal component analysis. Results of the PCA showed that $78.26 \%$ of the total variance was explained by the first principal components axis (PC1; eigenvalue $=5.237$ ) and the second principal components axis $(P C 2$; eigenvalue $=1.807)$. Plots of scores on PC1 and PC2 showed that most localities overlap. However, the Ao stock was concentrated at the origin of the coordinate system, at the same time, the other stocks were the second and third quadrants of the coordinate system. It is not obvious from here to see the differences between the eight stocks.

Nevertheless, as shape indices can create a classified function to differentiate individuals within a group, it differentiated the eight stocks with the accuracy of $54.5 \%$ in this study. The identification accuracy on the Ao stock was all correct, reaching $100 \%$. It proved that the Japanese stock of Ao can be significantly separated from the Chinese stocks 
in the three shape indicators selected (Roundness, Feret ratio, Surface density). On the contrary, there was a high chance of fake discrimination among $\mathrm{WH}, \mathrm{ZS}$ and YT locations because no significant difference can be found using multiple comparisons of shape indices among the three stocks. The same situation also appeared among DY stock and WZ stock. If the identification of a non-Japanese sample as Chinese stock was also regarded as a successful identification, the comprehensive discrimination rate would be reaching $99.5 \%$, because only one sample had an error in the identification.

In recent years, Fourier analysis has been proved to be an efficient method for studying and describing contour shapes of an otolith (Bani et al., 2013; Cadrin et al., 1999). In the present study, as the first two Fourier coefficients accounted for $40.59 \%$ of the overall variance in the principal component analysis, the distribution zones of eight stocks are overlapped in the plot, which is similar to the result from shape indices analysis. Consequently, principal component analysis for otolith shape could not efficiently distinguish $K$. punctatus stocks in this study.

Fisher's discriminant analysis classified $56.1 \%$ of individuals into correct stocks based on Fourier coefficients, which is a better method than the discriminant function using shape indices with only $54.5 \%$ accuracy for stock identification. Using the Fourier harmonic value of the otolith contour as the parameter for principal component analysis, 14 principal components were obtained. These 14 principal components together explained $95.06 \%$ of the difference, which was higher than the shape index method. So, it could better explain the shape changes of otoliths. In the discriminant analysis, although the accuracy rate of the Japanese group dropped from $100 \%$ to $81 \%$ of the Shape index, it was still the group with the highest accuracy rate, indicating that the otolith form of the Japanese stock and the Chinese stocks have a certain difference. The accuracy rate of discrimination among Chinese stocks was generally low, indicating that the shape of monstrous otoliths along the coast of China had not changed much.

Substantial intraspecific variations exist in sagitta shapes among $K$. punctatus stocks. Fisher's discriminant analysis can distinguish $K$. punctatus stocks based on the morphology of sagitta shapes. Based on the Fourier coefficient, Fisher's discriminant analysis accurately classified $56.1 \%$ specimens into correct stocks whereas the discriminant function of shape indices only correctly identified $54.5 \%$ specimens into right stocks. The difference of sagitta between the Japanese and Chinese stocks of $K$. punctatus can be manifested by multiple comparisons and fisher's discriminant analysis. In conclusion, morphometric analysis of otolith shapes could be used as a complementary tool along with body morphology to distinguish fish stocks.

\section{Acknowledgements}

This research is funded by National Key Research and Development Program of China (2019YFD0901301), Fundamental Research Funds for the Central Universities (No.XDJK2020C017) and Ecological restoration fund project of Agricultural Committee of Guizhou Province. All procedures performed were complied with the ethical standards and guidelines of Zhejiang Ocean University of China.

\section{References}

Bani A., Poursaeid S. and Tuset V. M., 2013. Comparative morphology of the sagittal otolith in three species of south caspian gobies. Journal of Fish Biology, 82(4):1321-1332 http://doi.org/10.1111/jfb.12073

Begg Gavin A and Waldman John R, 1999. An holistic approach to fish stock identification. Fisheries Research, 43(1-3):0-44 http://doi.org/10.1016/S01657836(99)00065-X

Cadrin Steven $\mathbf{X}$ and Friedland Kevin D, 1999. The utility of image processing techniques for morphometric analysis and stock identification. Fisheries Research, 43(1):129-139 http://doi.org/10.1016/S0165-7836(99)00070-3

Campana S. E. and Casselman J. M., 1993. Stock discrimination using otolith shapeanalysis. Canadian Journal of Fisheries and Aquatic Sciences, 50(5):1062-1083 http://doi.org/10.1139/f93-123 
Campana Steven E., 2004. Photographic atlas of fish otoliths of the northwest atlantic ocean canadian special publication of fisheries and aquatic sciences no. 133, Canada. http://doi.org/10.1139/9780660191089

Duarte-Neto Paulo, Lessa Rosangela, Stosic Borko and Morize Eric, 2008. The use of sagittal otoliths in discriminating stocks of common dolphinfish (coryphaena hippurus) off northeastern brazil using multishape descriptors. Ices Journal of Marine Science, 65(7):1144-1152 http://doi.org/10.1093/icesjms/fsn090

Dynesius M. and Jansson R., 2000. Evolutionary consequences of changes in species' geographical distributions driven by milankovitch climate oscillations. Proc. Natl. Acad. Sci. U. S. A., 97(16):9115-9120 http://doi.org/10.1073/pnas.97.16.9115

Goldstein Matthew and Dillon William R, 1978. Discrete discriminant analysis. Journal of the Royal Statistical Society, 142(3): http://doi.org/10.2307/2982498

Gwak Woo-Seok, Lee Yong-Deuk and Nakayama Kouji, 2015. Population structure and sequence divergence in the mitochondrial DNA control region of gizzard shad konosirus punctatus in korea and japan. Ichthyological Research, 62(3):379-385 http://doi.org/10.1007/s10228-014-0450-7

He Tao, Chen Cheng-jing, Qin Jian-guang, Li Yun, Wu Rong-hua and Gao Tianxiang, 2018. The Use of Otolith Shape to Identify Stocks of Redlip Mullet, Liza haematocheilus. Pakistan J. Zool, 2020:1-9 https://dx.doi.org/10.17582/journal.pjz/20180719080742

He Tao, Cheng Jiao, Qin Jian-guang, Li Yun and Gao Tian-xiang, 2017. Comparative analysis of otolith morphology in three species of scomber. Ichthyological Research, 65(2):192-201 http://doi.org/10.1007/s10228-017-0605-4

Humphreys W. F., Shiao J. C., Iizuka Y. and Tzeng W. N., 2006. Can otolith microchemistry reveal whether the blind cave gudgeon, milyeringa veritas (eleotridae), is diadromous within a subterranean estuary? Environmental Biology of Fishes, 75(4):439453 http://doi.org/10.1007/s10641-006-0012-6

Hutchings J. A., 2000. Collapse and recovery of marine fishes. Nature, 406(6798):882+ http://doi.org/10.1038/35022565

Jackson D. A., 1993. Stopping rules in principal components-analysis - a comparison of heuristic and statistical approaches. Ecology, 74(8):2204-2214 http://doi.org/10.2307/1939574

Kelly Brandon C., 2007. Some aspects of measurement error in linear regression of astronomical data. Astrophysical Journal, 665(2):1489-1506 http://doi.org/10.1086/519947

Larmuseau Maarten H. D., Van Houdt Jeroen K. J., Guelinckx Jef, Hellemans Bart and Volckaert Filip A. M., 2009. Distributional and demographic consequences of pleistocene climate fluctuations for a marine demersal fish in the north-eastern atlantic. Journal of Biogeography, 36(6):1138-1151 http://doi.org/10.1111/j.13652699.2008.02072.x

Liu J. X., Gao T. X., Wu S. F. and Zhang Y. P., 2007. Pleistocene isolation in the northwestern pacific marginal seas and limited dispersal in a marine fish, chelon haematocheilus (temminck \& schlegel, 1845). Mol. Ecol., 16(2):275-288 http://doi.org/10.1111/j.1365-294X.2006.03140.x

Lombarte A. and Cruz A., 2007. Otolith size trends in marine fish communities from different depth strata. Journal of Fish Biology, 71(1):53-76 http://doi.org/10.1111/j.10958649.2007.01465.x

Lombarte A. and Lleonart J., 1993. Otolith size changes related with body growth, habitat depth and temperature. Environmental Biology of Fishes, 37(3):297-306 http://doi.org/10.1007/bf00004637

Longmore Craig, Fogarty Kate, Neat Francis, Brophy Deirdre, Trueman Clive, Milton Andrew and Mariani Stefano, 2010. A comparison of otolith microchemistry and otolith shape analysis for the study of spatial variation in a deep-sea teleost, coryphaenoides rupestris. Environmental Biology of Fishes, 89(3-4):591-605 http://doi.org/10.1007/s10641-010-9674-1

Maggs C. A., Castilho R., Foltz D., Henzler C., Jolly M. T., Kelly J., Olsen J., Perez 
K. E., Stam W., Vainola R., Viard F. and Wares J., 2008. Evaluating signatures of glacial refugia for north atlantic benthic marine taxa. Ecology, 89(11):S108-S122 http://doi.org/10.1890/08-0257.1

Pavlov D. A. and Shirokova E. A., 2020. Variation of otolith structure in amur sleeper perccottus glenii (odontobutidae) populations from central russia. Journal of Ichthyology, 60(1):48-59 http://doi.org/10.1134/s0032945219060122

Ponton D., 2006. Is geometric morphometrics efficient for comparing otolith shape of different fish species? Journal of Morphology, 267(6):750-757 http://doi.org/10.1002/jmor.10439

Popper Arthur N., Ramcharitar John and Campana Steven E., 2005. Why otoliths? Insights from inner ear physiology and fisheries biology. Marine and Freshwater Research, 56(5): http://doi.org/10.1071/mf04267

Song Junjie, Dou Shuozeng, Cao Liang and Liu Jinhu, 2020. Sulcus and otolith outline analyses: Complementary tools for stock discrimination in white croaker pennahia argentata in northern chinese coastal waters. Journal of Oceanology and Limnology, http://doi.org/10.1007/s00343-020-0023-8

Tuset V. M., Lozano I. J., Gonzalez J. A., Pertusa J. F. and Garcia-Diaz M. M., 2003. Shape indices to identify regional differences in otolith morphology of comber, serranus cabrilla (I., 1758). Journal of Applied Ichthyology, 19(2):88-93 http://doi.org/10.1046/j.1439-0426.2003.00344.x

Vignon M. and Morat F., 2010. Environmental and genetic determinant of otolith shape revealed by a non-indigenous tropical fish. Mar. Ecol.-Prog. Ser., 411(231-241 http://doi.org/10.3354/meps08651

Wang P. X., 1999. Response of western pacific marginal seas to glacial cycles: Paleoceanographic and sedimentological features. Mar. Geol., 156(1-4):5-39 http://doi.org/10.1016/s0025-3227(98)00172-8 
The Israeli Journal of Aquaculture - Bamidgeh, IJA_72.2020.1134658, 12 pages

CCBY-NC-ND-4.0 • https://doi.org/10.46989/001c.21508

Table 3 The result of ANOVA between each two stocks between the nine shape index

\begin{tabular}{|c|c|c|c|c|c|c|c|}
\hline Stocks & WH & ZS & DY & $\mathrm{YT}$ & QD & WZ & AM \\
\hline WH & - & & & & & & \\
\hline ZS & & - & & & & & \\
\hline DY & $\mathrm{X}_{5}{ }^{*} \mathrm{X}_{7}{ }^{*} \mathrm{X}_{8}{ }^{*} \mathrm{X}_{9}{ }^{*}$ & $\mathrm{X}_{4}{ }^{*} \mathrm{X}_{7}{ }^{*} \mathrm{X}_{9}{ }^{*}$ & - & & & & \\
\hline YT & & & $\mathrm{X}_{6}{ }^{*} \mathrm{X}_{9}{ }^{*}$ & - & & & \\
\hline $\mathrm{HK}$ & $\mathrm{X}_{1}^{*} \mathrm{X}_{7}^{*} \mathrm{X}_{9}{ }^{*}$ & $X_{9}^{*}$ & $X_{2}^{*} X_{3}^{*} X_{4}^{*} X_{9}^{*}$ & $X_{9}{ }^{*}$ & - & & \\
\hline QD & $\mathrm{X}_{1}{ }^{*} \mathrm{X}_{5}{ }^{*} \mathrm{X}_{7}{ }^{*} \mathrm{X}_{8}{ }^{*} \mathrm{X}_{9}{ }^{*}$ & $\mathrm{X}_{1}^{*} \mathrm{X}_{5}{ }^{*} \mathrm{X}_{7}{ }^{*} \mathrm{X}_{8}{ }^{*} \mathrm{X}_{9}{ }^{*}$ & $\begin{array}{c}\mathrm{X}_{1}{ }^{*} \mathrm{X}_{2}{ }^{*} \mathrm{X}_{3}{ }^{*} \mathrm{X}_{4}{ }^{*} \mathrm{X}_{5}{ }^{*} \mathrm{X}_{7}{ }^{*} \\
\mathrm{X}_{8}{ }^{*}\end{array}$ & $\mathrm{X}_{1}{ }^{*} \mathrm{X}_{5}{ }^{*} \mathrm{X}_{7}{ }^{*} \mathrm{X}_{8}{ }^{*} \mathrm{X}_{9}{ }^{*}$ & $\mathrm{X}_{1}{ }^{*} \mathrm{X}_{5}{ }^{*} \mathrm{X}_{7}{ }^{*} \mathrm{X}_{8}{ }^{*} \mathrm{X}_{9}{ }^{*}$ & & \\
\hline WZ & $\mathrm{X}_{4}{ }^{*} \mathrm{X}_{9}{ }^{*}$ & $\mathrm{X}_{4}^{*} \mathrm{X}_{6}{ }^{*} \mathrm{X}_{9}{ }^{*}$ & & $\mathrm{X}_{4}^{*} \mathrm{X}_{6}{ }^{*} \mathrm{X}_{9}{ }^{*}$ & 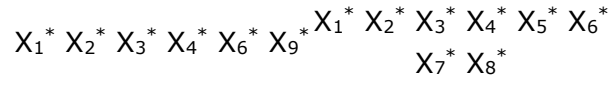 & $6^{*}$ & \\
\hline AM & $\mathrm{X}_{1}^{*} \mathrm{X}_{5}^{*} \mathrm{X}_{6}^{*} \mathrm{X}_{7}^{*} \mathrm{X}_{8}^{*} \mathrm{X}_{9}^{*}$ & $\mathrm{X}_{1}^{*} \mathrm{X}_{5}^{*} \mathrm{X}_{7}^{*} \mathrm{X}_{8}^{*} \mathrm{X}_{9}^{*}$ & $\begin{array}{c}\mathrm{X}_{1}{ }^{*} \mathrm{X}_{2}{ }^{*} \mathrm{X}_{3}{ }^{*} \mathrm{X}_{5}{ }^{*} \mathrm{X}_{6}{ }^{*} \mathrm{X}_{7}{ }^{*} \\
\mathrm{X}_{8}{ }^{*} \mathrm{X}_{9}{ }^{*}\end{array}$ & $\mathrm{X}_{1}^{*} \mathrm{X}_{5}^{*} \mathrm{X}_{7}^{*} \mathrm{X}_{8}{ }^{*} \mathrm{X}_{9}{ }^{*}$ & $\mathrm{X}_{1}{ }^{*} \mathrm{X}_{5}{ }^{*} \mathrm{X}_{6}{ }^{*} \mathrm{X}_{7}{ }^{*} \mathrm{X}_{8}{ }^{*} \mathrm{X}_{9}{ }^{*} \mathrm{X}_{1}{ }^{*} \mathrm{X}_{5}{ }^{*} \mathrm{X}_{6}{ }^{*} \mathrm{X}_{7}{ }^{*} \mathrm{X}_{8}{ }^{*} \mathrm{X}_{9}{ }^{*}$ & $\begin{array}{c}{ }^{*} \mathrm{X}_{1}^{*} \mathrm{X}_{2}{ }^{*} \mathrm{X}_{3}{ }^{*} \mathrm{X}_{4}{ }^{*} \mathrm{X}_{5}{ }^{*} \mathrm{X}_{6}{ }^{*} \\
\mathrm{X}_{7}{ }^{*} \mathrm{X}_{8}{ }^{*} \mathrm{X}_{9}{ }^{*}\end{array}$ & - \\
\hline
\end{tabular}

"*" indicates a significant difference. Where $X_{1}$ is Roundness, $X_{2}$ is Form-factor, $X_{3}$ is Circularity, $X_{4}$ is Rectangularity, $X_{5}$ is Ellipticity, $X_{6}$ is Radius ratio, $X_{7}$ is Feret ratio, $\mathrm{X}_{8}$ is Aspect ratio, $\mathrm{X}_{9}$ is Surface Density.

* Corresponding author. Tel.: +86 2368251196, e-mail: hh1985@swu.edu.cn; gaotianxiang0611@163.com; sushengqi@swu.edu.cn 